\title{
GÊNERO, VOLTE PARA O ARMÁRIO! DISCURSO RELIGIOSO, GÊNERO E MODELAGEM DE COMPORTAMENTO
}

\author{
GÉNERO, VOLVER AL GABINETE! EL DISCURSO RELIGIOSO, \\ GÉNERO Y MODELADO DE LA CONDUCTA
}

\section{GENDER, GO BACK TO THE CLOSET! RELIGIOUS SPEECH, GENDER AND BEHAVIOR PATTERNS}

\author{
Rodrigo Pedro CASTELEIRA ${ }^{1}$ \\ Eliane Rose $\mathrm{MAIO}^{2}$
}

RESUMO: A proposta do presente artigo é a de discutir as questões sobre o conceito de gênero, que envolveram as discussões sobre o Plano Municipal de Educação (PME), aliado com os conceitos sobre modelagem de comportamento e educação sob uma estrutura skinneriana. Além disso, o discurso religioso veiculado pelo Conselho Nacional de Bispos do Brasil (CNBB) parece tentar modelar o comportamento, a fim de que as pessoas rejeitem a própria palavra 'gênero' nos documentos, ignorando as bases legais na educação. Os resultados teóricos revelam em que medida os argumentos religiosos tentam controlar ou alterar as contingências humanas, entre elas a educacional, com o uso do reforço verbal condicionando-o à ideia de possibilidade de céu ou inferno.

PALAVRAS-CHAVE: Gênero. Educação. Comportamento. Religião.

RESUMEN: El propósito de este artículo es discutir las cuestiones sobre el concepto de género junto a debates sobre el Plan Municipal de Educación (PME) y con los conceptos de modelado de la conducta y la educación bajo de una estructura de Skinner. Por otra parte, el discurso religioso transmitido por el Consejo Nacional de Obispos de Brasil (CNBB) parece intentar modelar el comportamiento, con el fin de que las personas rechazan la palabra "género" en los documentos, haciendo caso omiso de las bases legales de la formación. Los resultados teóricos revelan el grado en que los argumentos religiosos tratan de controlar o cambiar las contingencias humanas, incluyendo la educación, con el uso de refuerzo verbal acondicionado a la idea de la posibilidad de que el cielo o el infierno.

PALAVRAS CLAVE: Género. Educación. Comportamiento. Religión.

1 Doutorando em educação, pelo Departamento em Educação, Universidade Estadual de Maringá. Professor de filosofia na rede pública paranaense. Email: pccasteleira@gmail.com

${ }^{2}$ Docente da Universidade Estadual de Maringá, no Departamento de Teoria e Prática da Educação. Doutora e Pós-doutorado em Educação Escolar pela UNESP/Araraquara. Email: elianerosemaio@yahoo.com.br 
ABSTRACT: This paper proposal is debating questions on the concept of gender which is involved in discussions about the City Educational Plan, together with the concepts on behavior patterns and education under the Skinner structuralism. In addition to that, the religious speech conducted by the Brazil's Bishops National Council looks as if it were trying to pattern the behavior in order to make people reject the word 'gender' itself in documents ignoring the legal basis of education. The theoretical results reveal to what extent the religious arguments try to control or change the human contingencies, among all of them the educational contingency, through using the verbal reinforcement converting the behavior to the idea of heaven or hell possibilities.

KEYWORDS: Gender. Education. Behavior. Religion.

\section{Introdução}

O que se pretende é comparar a postura do Conselho Nacional de Bispos do Brasil (CNBB), ao veicular uma carta para que o gênero não seja discutido nos Planos Municipais de Educação, como elemento de modelagem de comportamento, descrita por Skinner (1972, 2003), além de suscitar teorias e documentos educacionais que legitimam tais discussões. A escolha por Skinner se efetiva por ter investigado como o comportamento pode ser modelado nas chamadas agências de controle, a saber, "o governo, a religião, a educação, a economia e a indústria -, ou ainda em um quarto estado (fourth estate, Skinner, 1989, p. 120), constituído pela mídia, por professores, cientistas e acadêmicos" (ABIB, 2001, p. 107). O comportamento, então, pode ser modelado segundo os documentos legais, como os PMEs, uma vez que parte de agências de controle.

Os Planos Municipais de Educação (PME) são diretrizes educacionais que seguem as orientações ditadas no Plano Nacional de Educação, conforme a Lei $\mathrm{n}^{\circ}$ 13.005, de junho de 2014 (BRASIL, 2014), que tem uma proposta decenal e de erradicação do analfabetismo, além de uma agenda de propostas para uma educação de qualidade a todas as pessoas, conforme o art. $2^{\circ}$ :

I - erradicação do analfabetismo;

II - universalização do atendimento escolar;

III - superação das desigualdades educacionais, com ênfase na promoção da cidadania e na erradicação de todas as formas de discriminação;

IV - melhoria da qualidade da educação; 
V - formação para o trabalho e para a cidadania, com ênfase nos valores morais e éticos em que se fundamenta a sociedade;

VI - promoção do princípio da gestão democrática da educação pública;

VII - promoção humanística, científica, cultural e tecnológica do País;

VIII - estabelecimento de meta de aplicação de recursos públicos em educação como proporção do Produto Interno Bruto - PIB, que assegure atendimento às necessidades de expansão, com padrão de qualidade e equidade;

IX - valorização dos (as) profissionais da educação;

$\mathrm{X}$ - promoção dos princípios do respeito aos direitos humanos, à diversidade e à sustentabilidade socioambiental (BRASIL, 2014, s/p).

No documento todo inexiste o termo gênero, o que poderia ser uma justificativa para que os demais PME não o mencionassem em suas redações, porém, nos anexos da referida lei existem as Metas e Estratégias, entre elas a que visa garantir o combate às violências sexuais nas escolas e lares:

7. 23) garantir políticas de combate à violência na escola, inclusive pelo desenvolvimento de ações destinadas à capacitação de educadores para detecção dos sinais de suas causas, como a violência doméstica e sexual, favorecendo a adoção das providências adequadas para promover a construção da cultura de paz e um ambiente escolar dotado de segurança para a comunidade (BRASIL, 2014, s/p.).

Uma das formas de violência que perpassa a educação é a de gênero e, ainda que não exista o termo, não implica em não trabalhá-lo. No Brasil, segundo consta no IBGE, a institucionalização dessas questões se inicia com a criação do Conselho Nacional dos Direitos da Mulher, em 1985, e da Secretaria de Políticas para as Mulheres, em 2003, o que propiciou as discussões e implementações de agendas e políticas voltadas "[...] à realização dos direitos das mulheres e ao combate às discriminações e desigualdades de gênero no País" (IBGE, 2014, p. 10).

O conceito de gênero, então, se conecta com as discussões iniciadas com os movimentos feministas, que desde "[...] os anos sessenta do século passado" (JUNIOR, 2011, p. 36) trouxeram a discussão sobre a desnaturalização do poder masculino suscitando "as teóricas que fundaram os estudos de gênero, que instituíram essa categoria para a análise das relações sociais e, notadamente, para estudar a relação entre os sexos" (Idem, p. 36). As teóricas feministas (HARAWAY, 2009; BUTLER, 2003) chamam a atenção para um campo não apenas calcado nos conceitos biológicos para as definições de feminino e masculino, mas também dimensionadas com os modelos organizados de uma determinada sociedade e cultural, social e historicamente firmados. 
Depois do reconhecimento, arduamente conquistado, de que o gênero, a raça e a classe são social e historicamente constituídos, esses elementos não podem mais formar a base da crença em uma unidade "essencial". Não existe nada no fato de ser "mulher" que naturalmente una as mulheres. Não existe nem mesmo uma tal situação - "ser" mulher. Trata-se, ela própria, de uma categoria altamente complexa, construída por meio de discursos científicos sexuais e de outras práticas sociais questionáveis. A consciência de classe, de raça ou de gênero é uma conquista que nos foi imposta pela terrível experiência histórica das realidades sociais contraditórias do capitalismo, do colonialismo e do patriarcado (HARAWAY, 2009, p. 47).

Judith Butler (2003) afirma que o gênero pode ser compreendido como uma fabricação sob processos internos, uma fantasia que envolve as fronteiras corporais, nada mais destitui a conclusão de que não sejam falsos ou verdadeiros, apenas produtos de um discurso acerca de uma identidade 'primária e estável'.

Essas performances gestuais, de condutas e corporeidades representam produtos manufaturados firmados por discursos (políticos). O Conselho Nacional de Bispos do Brasil (CNBB), por sua vez, veiculou pelo país sua posição acerca dessa discussão e inserção do termo gênero nos PME, articulando um discurso com uma possibilidade antropológica aliado à possibilidade de desconstrução familiar por causa da chamada ‘ideologia de gênero', termo utilizado pelo documento, conforme se pode ler abaixo.

A tentativa de inclusão da ideologia de gênero nos Planos Estaduais e Municipais de Educação contraria o Plano Nacional de Educação, aprovado no ano passado pelo Congresso Nacional, que rejeitou tal expressão. Pretender que a identidade sexual seja uma construção eminentemente cultural, com a consequente escolha pessoal, como propõe a ideologia de gênero, não é caminho para combater a discriminação das pessoas por causa de sua orientação sexual. $\mathrm{O}$ pressuposto antropológico de uma visão integral do ser humano, fundamentada nos valores humanos e éticos, identidade histórica do povo brasileiro, é que deve nortear os Planos de Educação. A ideologia de gênero vai no caminho oposto e desconstrói o conceito de família, que tem seu fundamento na união estável entre homem e mulher. A introdução dessa ideologia na prática pedagógica das escolas trará consequências desastrosas para a vida das crianças e das famílias. O mais grave é que se quer introduzir esta proposta de forma silenciosa nos Planos Municipais de Educação, sem que os maiores interessados, que são os pais e educadores, tenham sido chamados para discuti-la. A ausência da sociedade civil na discussão sobre o modelo de educação a ser adotado fere o direito das famílias de definir as bases e as diretrizes da educação que desejam para seus filhos. A CNBB reafirma o compromisso da Igreja em se somar aos que combatem todo tipo de discriminação a fim de que tenhamos uma sociedade sempre mais fraterna e solidária. Confia que a sociedade e o Estado cumpram seu direito e dever de oferecer a toda pessoa os 
meios necessários para uma educação livre e autêntica (Cf. CNBB Doc. 47, n. 73). Reafirma também o papel insubstituível dos pais na educação de seus filhos e primeiros responsáveis por introduzi-los na vida em sociedade (ARQUIDIOCESE DE MARINGÁ, 2015, s/p.).

Interessante notar o termo 'ideologia de gênero', que nenhum texto dos estudos de gênero menciona, e o conceito de destruição da família ou de suas bases, proposta também não mencionada por movimentos sociais, por exemplo. A proposta de inserção do termo gênero, substituída por sexo, não promoveria uma dinâmica de perigo às bases familiares e religiosas, aliás, a nota da CBNN não explicita abertamente quais as consequências desastrosas "para a vida das crianças e das famílias" (ARQUIDIOCESE DE MARINGÁ, 2015, s/p.).

No dia 26 de março de 2015, na cidade de Apucarana, Paraná, o Conselho Episcopal Regional Sul, afiliado à CNBB, emitiu uma mensagem ao povo paranaense com a postura de discordância da divulgação e da inserção da ideologia de gênero nos espaços escolares.

Discordamos, sobremaneira, da divulgação e implantação da ideologia de gênero, de modo particular nas Escolas. Defendemos o direito dos pais de serem ouvidos e decidirem sobre os projetos de educação dos seus filhos, nas Escolas em que eles estiverem matriculados. Reafirmamos a prioridade da família, fundada no sacramento do matrimônio entre um homem e uma mulher, como escola de valores, educadora da fé e formadora de cidadãos (ARQUIDIOCESE DE MARINGÁ, 2015, s/p.).

Esses documentos emitidos parecem querer determinar quais discussões podem ou não estar nos espaços escolares, talvez ainda um traço jesuítico, desconsiderando os documentos que legitimam uma dinâmica para o enfretamento das violências e para uma educação emancipadora com igualdade. Na concepção de Gomes (2007), que trabalha com o conceito de diversidade e currículo, tal posição religiosa poderia ser justificada por não concordar com uma emancipação colonizadora e dominadora que os traços jesuíticos marcaram por anos na educação brasileira.

Os Parâmetros Curriculares Nacionais (PCN) (BRASIL, 1997) indicam de forma objetiva quais as ações norteadoras para a educação, sobretudo em seu Caderno 10, intitulado Pluralidade Cultural e Orientação Sexual, em que pontua uma proposta curricular voltada para a cidadania e que "deve preocupar-se necessariamente com as diversidades existentes na sociedade, uma das bases concretas em que se praticam os preceitos ético" (BRASIL, 1997. p. 129). O tema do Caderno 10 não se constitui apenas 
como um conjunto de informações para o universo escolar, mas como proposta intervencionista, transversal e de tomada de consciência de si enquanto sujeito.

O tema Orientação Sexual não tem apenas um caráter informativo, como sugerem os PCNs, mas sobretudo um efeito de intervenção no interior do espaço escolar. Concebido como tendo uma função transversal que atravessa fronteiras disciplinares, ele se dissemina por todo campo pedagógico e funciona de forma a expandir seus efeitos em domínios dos mais heterogêneos. Os PCNs incitam a escola a, através de práticas pedagógicas diversas, construir e mediar a relação do sujeito consigo mesmo, de modo a fazer com que o indivíduo tome a si mesmo como objeto de cuidados, alterando comportamentos. Através da colocação do sexo em discurso, parece haver um complexo aumento do controle sobre os indivíduos, o qual se exerce não tanto através de proibições e punições, mas através de mecanismos, metodologias e práticas que visam a produzir sujeitos autodisciplinados no que se refere à maneira de viver sua sexualidade (ALTMANN, 2011, p. 584).

As diversidades representam uma marca que merece respeito enquanto direito básico das pessoas (CANDAU, 2008; CANDAU, 2011; JÚNIOR, 2011) e o entrelaçamento com outros temas transversais será emblemático no tratamento de tais direitos individuais, "nas relações de gênero, no campo da saúde, na questão ambiental, na temática do trabalho e consumo [...]” (AGUIAR et.al., 2006, p. 163). Este autor chama a atenção para o Programa Nacional de Fortalecimento dos Conselhos Escolares e que objetiva subsidiar "[...] às secretarias estaduais e municipais de educação na realização de capacitações de conselheiros escolares, seja por meio de cursos presenciais ou a distância" (Idem, p. 8-9), além de poder estimular os debates entre as pessoas que participam dos Conselhos. Em uma das recomendações é possível notar a indicação para a valorização de suas culturas e historicidades, bem como a de gênero.

Nessa direção, a escola pode propiciar a organização de situações que favoreçam ao estudante efetivar aprendizagens que o leve a valorizar a história do seu bairro, dos líderes populares do seu lugar, da sua raça, do seu gênero e da sua classe social. Incentivar no corpo discente o desenvolvimento de posturas solidárias, críticas e criativas e propiciar a organização de situações que induzam o estudante a lutar pelos seus sonhos são tarefas de uma escola comprometida com a formação cidadã (AGUIAR et al., 2006, p. 45).

Em 2007, por exemplo, foram criados os chamados Princípios de Yogyakarta (BRASIL, 2007), um documento sobre a aplicação da Legislação Internacional de Direitos Humanos no tocante à orientação sexual e identidade de gênero. Os princípios se destinam a uma gama de "normas de direitos humanos e de sua aplicação a questões 
de orientação sexual e identidade de gênero" (BRASIL, 2007, p. 8), firmam detalhadamente quais as obrigações dos Estados para que essas politicas se efetivem, porém, os especialistas "também enfatizam que muitos outros atores têm responsabilidades na promoção e proteção dos direitos humanos” (Idem, p. 8). Esses princípios, conforme o próprio documento, se constituem como prerrogativas jurídicas internacionais a fim de orientar os Estados a garantir em que toda e qualquer pessoa usufrua de seus direitos que são "natos e preciosos" (BRASIL, 2007, p. 9).

Dentro dos Princípios dispostos, que totalizam 29, existe o Princípio 16, sobre o direito à educação e como os Estados devem respeitas as características da orientação sexual e identidade de gênero:

Toda pessoa tem o direito educação, sem discriminação por motivo de sua orientação sexual e identidade de gênero, e respeitando essas características.

Os Estados deverão:

d) Garantir que os métodos educacionais, currículos e recursos sirvam para melhorar a compreensão e o respeito pelas diversas orientações sexuais e identidades de gênero, incluindo as necessidades particulares de estudantes, seus pais e familiares (BRASIL, 2007, p. 23).

As relações de diversidade discutidas por Gomes (2007) vão ao encontro desses princípios no universo da educação. A educação deve primar pela desconstrução da naturalização que os processos dominadores instauraram e que implicaram em inferiorização em determinados grupos, o que é possível quando se incorpora nos livros didáticos, no currículo, "no plano de aula, nos projetos pedagógicos das escolas os saberes produzidos pelas diversas áreas e ciências articulados com os saberes produzidos pelos movimentos sociais e pela comunidade" (GOMES, 2007, p. 25).

Essas relações de gênero, mas também de toda a diversidade, representa um multiculturalismo proposto por Candau (2008, p. 51), que considera uma vertente em que a interculturalidade seja acentuada por ajudar na "[...] construção de sociedades, democráticas e inclusivas, que articulem políticas de igualdade com políticas de identidade". Para a autora, a inter-relação entre diferentes grupos culturais é benéfica, pois rompe com o paradigma de essencialidade de culturas e identidades culturais, e instaura uma perspectiva de culturas em processos constantes de construção e reconstrução, sem desconsiderar a existência de raízes fundantes, mas que as mesmas são dinâmicas e históricas. O multiculturalismo deve ser crítico e de resistência para que 
vá ao encontro de uma agenda política de mudanças frente às estruturas de poder que vigoram.

O multiculturalismo crítico e de resistência parte da afirmação de que o multiculturalismo tem de ser situado a partir de uma agenda política de transformação, sem a qual corre o risco de se reduzir a outra forma de acomodação à ordem social vigente. Entende as representações de raça, gênero e classe como produto das lutas sociais sobre signos e significações (CANDAU, 2008, p. 51).

As agendas políticas podem, por exemplo, solicitar o direito à educação, conforme o Artigo 205, da Constituição Federal de 1988, "a educação, direito de todos e dever do Estado e da família, será promovida e incentivada com a colaboração da sociedade, visando ao pleno desenvolvimento da pessoa, seu preparo para o exercício da cidadania e sua qualificação para o trabalho" (BRASIL, 1988, s/p), além de pontuar em seu Artigo 206 que deve haver condições para acesso, permanência, liberdade de ensinar e aprender, bem como o pluralismo de ideias e concepções pedagógicas.

A definição de currículo, como revelam Lopes e Macedo (2011), não se constitui tarefa fácil, uma vez que as teorias ou são negadas ou surgem mais elementos que possam acrescentar, ou ainda podem ser mantidas, todavia, o trabalho parte dos elementos mais básicos dispostos pelas autoras frente ao currículo: uma seleção e organização do que se ensina; que o currículo ensina conhecimentos técnicos, além das relações de poder, hegemonia e ideologia; prática de significação e condução para o que se fazer, ainda que parcialmente.

O currículo não está descolado da temática identitária, e nem cultural, tanto que no Brasil essa questão se iniciou primeiro com as questões étnicas, porém, "ainda que a produção teórica em torno da afirmação dessas identidades no país venha aumentando consideravelmente, ainda é pouco expressiva no campo do currículo" (LOPES, MACEDO, 2011, p. 217).

Silva (2010), por exemplo, descreve o currículo como um espaço, um campo em que se produza e se crie significados, sentidos que soam de áreas diversas uma vez que ele trabalha sobre materiais culturais existentes, bem como as identidades nelas encontradas. Se as identidades encontradas nos espaços fogem da norma, como um desviante (BECKER, 2008), a educação deve repensar sua estrutura curricular para que contemple também essas identidades, como as questões étnico-raciais e de gênero. 


\section{Comportamento e educação em Skinner e a modelagem inferida sob o gênero}

Skinner (2003) defende que parece haver naturalizações (sociais e históricas) que imprimem no comportamento uma modelagem, uma estrutura de modificação comportamental. O autor descreve como isso afetaria a educação, no entanto, o que é ele? O comportamento precisa ser descrito para que se torne um objeto epistemológico a fim de relacioná-lo com a modelagem sob o uso do termo 'gênero'. Ele não exige que se adote um paradigma distinto do científico, mas que se amplie "[...] o conhecimento das variáveis que afetam o sistema inteiro e a criação de técnicas e tecnologias capazes de alimentar constantemente um banco de informações a ser usado na previsão de eventos comportamentais particulares" (NETO, 2002, p. 4). Por mais que se tente definir o que ele seja, Skinner defende que delimitar o que o comportamento é demanda dificuldade, dada sua mutabilidade.

O comportamento é uma matéria difícil, não porque seja inacessível, mas porque é extremamente complexo. Desde que é um processo, e não uma coisa, não pode ser facilmente imobilizado para observação. É mutável, fluido e evanescente, e, por esta razão, faz grandes exigências técnicas da engenhosidade e energia do cientista. Contudo, não há essencialmente insolúvel nos problemas que surgem deste fato (SKINNER, 2003, p. 16).

Como o autor define, não existe uma análise do que seja o comportamento humano de forma cristalizada, dada sua dinâmica fluídica, mutante e cambiável, no entanto, existe a possibilidade de mapear ou ao menos compreender uma resposta frente a uma ação, o que o autor chama de causa e efeito. Aqui proponho, deliberadamente, a possibilidade de uma tentativa de modificação comportamental na educação com a retirada do termo gênero dos documentos sob os argumentos religiosos dispostos. $\mathrm{Ou}$ seja, parece haver uma tentativa de alteração do comportamento educacional com a influência dos discursos religiosos pautados em doutrinas específicas, desconsiderando a laicidade do Estado e o art. 19 da Constituição Federal de 1988 (BRASIL, 1988, s/p):

\footnotetext{
Art. 19. É vedado à União, aos Estados, ao Distrito Federal e aos Municípios:

I - estabelecer cultos religiosos ou igrejas, subvencioná-los, embaraçar-lhes o funcionamento ou manter com eles ou seus representantes relações de dependência ou aliança, ressalvada, na forma da lei, a colaboração de interesse público;

II - recusar fé aos documentos públicos;

III - criar distinções entre brasileiros ou preferências entre si.
} 
Ogasawara (2009) defende que o comportamento humano não é livre, bem como que toda e qualquer ação ou evento deve ser considerado para efeitos de previsões. Com efeito, é possível o controle comportamental na medida em que se possa manipulá-lo. A pessoa, por exemplo, ainda que possa tentar observar o funcionamento fisiológico de seu próprio corpo, não significa que estabelecerá as causas de seu comportamento, uma vez que se faz necessário também o estudo do ambiente (OGASAWARA, 2009). Skinner (2003) desenvolve um conceito chamado de comportamento operante, que se trata de um ato voluntário, e suas consequências possibilitam determinar a probabilidade de que ocorra, mas, como sugere Ogasawara (2009, p. 16), se faz necessária a compreensão do que seja o condicionamento operante.

O condicionamento operante é um processo no qual se pretende condicionar uma resposta de um indivíduo, seja para aumentar a sua probabilidade de ocorrência ou para extingui-la. No primeiro caso, são apresentados reforços toda vez que o sujeito apresenta a resposta adequada. Vale ressaltar que o conceito de reforço está diretamente ligado a ocorrência da resposta, um estímulo só pode ser considerado reforçador se aumentar a probabilidade do comportamento ocorrer. $\mathrm{O}$ reforço pode ser positivo quando é apresentado algo ao indivíduo ou negativo quando se retira algo do ambiente. Percebe-se, com isso, que, diferentemente do que se diz, reforço não é sinônimo de recompensa.

Parece haver uma tentativa de controle por parte da instituição religiosa do termo 'gênero' como uma possibilidade de modificar o comportamento. Para Skinner (2003, p. 383), o controle que parte de uma agência religiosa está calcado na “[...] conexão com o sobrenatural, através da qual a agência arranja ou altera certas contingências que acarretam boa ou má sorte no futuro imediato, ou bênção eterna ou danação na vida por vir". Desta forma, o comportamento não seria definido como mau ou bom, ilegal ou legal, mas virtuoso ou pecaminoso, sendo "reforçado ou punido de acordo" (Idem, p. 384). Essas relações religiosas perpassam o sistema educacional e imprimem poder como reforço verbal condicionado à possibilidade de céu ou inferno, como uma estrutura similar ao que ocorre com o ensino.

Skinner (1972), ao escrever Tecnologia do Ensino, observa que os comportamentos dos organismos individuais são previsíveis do contexto estatístico e que prever as respostas só seria possível graças a uma série inferências. O comportamento, segundo o autor, no campo da aprendizagem, pode ser observado conforme duas principais melhorias: a primeira seria a Lei do Efeito, que possibilita a 
modelagem comportamental, e a segunda, que permite manter o controle sobre o comportamento por mais tempo.

\begin{abstract}
A Lei do Efeito tem sido levada a sério; temo-nos assegurado de que os efeitos aconteçam e de que aconteçam em circunstâncias ótimas para a produção de modificações chamadas aprendizagem. Uma vez arranjado o tipo particular de consequência chamado reforçador, as técnicas nos permitem modelar o comportamento de um organismo quase à vontade [...]. Um segundo e importante progresso na técnica permite manter o comportamento em dado estado de força por longos períodos de tempo. Reforços, é claro, continuam a ser importantes mesmo muito depois de o organismo ter aprendido como fazer algo, mesmo depois de ter adquirido o comportamento. São necessários para manter o comportamento fortalecido (SKINNER, 1972, p. 9-10).
\end{abstract}

Ao pensar uma lógica educacional que receba influências religiosas para modelar o comportamento das práticas pedagógicas, ainda que legitimadas legalmente, como os PCN (BRASIL, 1997, s/p), fica patente o poder que uma instituição religiosa dispõe, desde que ele seja marcado por determinados reforçadores verbais condicionantes.

O poder conseguido pela agência religiosa depende de quão eficientemente certos reforçadores verbais são condicionados particularmente a promessa do Céu e a ameaça do Inferno. A educação religiosa contribui para esse poder emparelhando os termos com vários reforçadores condicionados e incondicionados que essencialmente são aqueles à disposição do grupo ético e das agências governamentais (SKINNER, 2003, p. 385).

Essa relação de poder se choca com as disposições contidas nos PCN (BRASIL, 1997) que tratam das discussões que se relacionam com o gênero (Idem, p. 149) ou orientação sexual (p. 134). Como se pode notar, o documento traz os termos em sua redação, servindo como parâmetros que responsabilizam à escola tais discussões, a fim de garantir uma "edificação da cidadania" (CORREA, 2013, p. 47).

As modificações no modo de pensar a sexualidade refletem-se em diversas áreas da sociedade. Na educação, os Parâmetros Curriculares Nacionais (PCN) (BRASIL, 1998) passam a admitir a responsabilidade da escola para discussões que envolvem a orientação sexual, o gênero e outros tópicos que abordam, de forma geral, a constituição de uma identidade nas pessoas (CORREA, 2013, 47).

Interessante notar que a autora fala em modificações nas estruturas do pensamento e na responsabilidade da escola em abordar questões de gênero. Se antes 
dos PCN (BRASIL, 1997) inexistiam as discussões sobre gênero e orientação sexual, por exemplo, as indicações já citadas revelam a possibilidade em se modificar a estrutura de pensamento ou, como defende Skinner (1972), identificar um padrão e alterá-lo.

O padrão pode ser tão simples como uma frequência constante de resposta a um dado valor; pode ser uma frequência que o desempenho característico de um dado esquema pode ser uma mudança brusca, a partir de completa ausência de respostas para determinada frequência estável e alta. Já foi demonstrado que o desempenho caraterístico de um dado esquema pode ser posto sob o controle de um estímulo particular e que diferentes desempenhos podem ser postos sob o controle de estímulos diferentes para o mesmo organismo. Em um experimento, desempenhos apropriados de nove esquemas diferentes foram postos sob o controle de estímulos correspondentes apresentados ao acaso. Quando o Estímulo 1 estava presente, o pombo executava o repertório apropriado ao Esquema 1. Quando o Estímulo 2 estava presente, o pombo executava o repertório apropriado ao Esquema 2. E assim por diante. Este resultado é importante, porque faz com que seja muito mais plausível a extrapolação dos resultados de laboratório para a vida diária. Estamos constantemente mudando de esquema para esquema à medida que o ambiente muda (SKINNER, 1972, p. 12).

Essas análises do autor, ainda que com organismos mais simples, como pombos, ilustram como uma sequência simples pode ser executada, bem como mais complexas. Da mesma forma, se antes o gênero não era discutido nos documentos legais na educação, as pesquisas e teorias feministas o trouxeram à tona modificando o padrão social, o que se espraia nos espaços escolares a ponto de que os currículos sejam repensados. Se antes o esquema era pensado sob uma ótica do universal masculino, significa que os repertórios educacionais representavam uma estrutura à época em que foram elaborados, no entanto, ao modificar tais repertórios, modificam-se os esquemas.

\section{Considerações Finais}

Os preceitos educacionais e políticos dispostos pela CNBB, além de servir como estrutura de modelagem para seus pares, parece querer que estes repassem os mesmos esquemas aos espaços educacionais. Ao desconsiderar o conceito de gênero nos espaços escolares e mesmo tentar impedir suas discussões, impedem-se as manifestações pertinentes à diversidade que estão presentes nos espaços escolares. A carta emitida pela CNBB parece uma tentativa de (re)formatar o comportamento das pessoas a fim de que 
a modelagem implique na inexistência ou rejeição do termo, ignorando as recomendações legais e, talvez, promovendo os preconceitos e desigualdades.

\section{Referências}

ABIB, José Antônio Damásio. Teoria Moral de Skinner e Desenvolvimento Humano. Psicologia: Reflexão e Crítica, 14(1), p.107-117, 2001.

ALMEIDA, Laurinda Ramalho de. Das relações entre educação e psicologia na perspectiva de uma educadora. In: Revista Semestral da Associação Brasileira de Psicologia Escolar e Educacional, SP. Volume 16, Número 2, p. 341-348, julho/dezembro de 2012.

AGUIAR, Márcia Ângela da Silva et. al. Conselho Escolar e a relação entre a escola e o desenvolvimento com igualdade social. Brasília: Ministério da Educação, Secretaria de Educação Básica, 2006.

ALTMANN, Helena. Orientação sexual nos parâmetros curriculares nacionais. In: Estudos feministas, Ano 9, p. 575-585, segundo semestre de 2001.

ARQUIDIOCESE DE MARINGÁ. CNBB divulga nota sobre a inclusão da ideologia de gênero nos Planos de Educação. Disponível em: $<$ http://arquidiocesedemaringa.org.br/noticiasigreja/cnbb-divulga-nota-sobre-ainclusao-da-ideologia-de-genero-nos-planos-de-educacao/>. Acesso em: 27 de jul. 2015.

BECKER, Howard S. Outsiders: estudos de sociologia do desvio. Trad. Maria Luiza X. de A. Borges. Rio de Janeiro, Zahar Ed., 2008.

BRASIL. Secretaria de Educação Fundamental. Parâmetros curriculares nacionais: pluralidade cultural, orientação sexual. Secretaria de Educação Fundamental. - Brasília: MEC/SEF, 1997.

BRASIL. Secretaria de Educação Fundamental. Parâmetros curriculares nacionais: apresentação dos temas transversais, ética. Secretaria de Educação Fundamental. Brasília: MEC/SEF, 1997.

BRASIL. Plano Nacional de Educação, Lei n. 13.005, de 25 de junho de 2014. Brasília: Presidência da República, 2014.

BRASIL. PRINCÍPIOS DE YOGYAKARTA. Princípios sobre a aplicação da legislação internacional de direitos humanos em relação à orientação sexual e identidade de gênero. 2007. Disponível em: <http://www.dhnet.org.br/direitos/sos/gays/principios_de_yogyakarta.pdf >. Acesso em: 03 de ago. 2015.

BUTLER, Judith. Problemas de gênero: feminismo e subversão da identidade. Trad. Renato Aguiar. Rio de Janeiro, Civilização Brasileira Ed., 2003. 
CANDAU, V. M. (Org.). A formação de educadores: uma perspectiva multidimensional. In: CANDAU, V. M. (Orgs.). Rumo a uma nova didática. $19^{\mathrm{a}} \mathrm{Ed}$. Petrópolis/RJ: Vozes, 2008.

CANDAU, V. M. Direitos Humanos, educação e interculturalidade: as tensões entre igualdade e diferença. In: Revista Brasileira de Educação. Volume 13, n. 37, p. 45-56. jan-abr, 2008.

CANDAU, Vera Maria Ferrão. Diferenças culturais, cotidiano escolar e práticas pedagógicas. Currículo sem Fronteiras, v.11, n.2, p. 240-255, jul/dez 2011.

CORREA, Crishna Mirella de Andrade. Educação, Lei e Sexualidade: a importância da discussão sobre os padrões normativos do comportamento sexual e de gênero na escola. In: MAIO, Eliane Rose; CORREA, Crishna Mirella de Andrade (Org.). Gênero, direitos e diversidade sexual trajetórias escolares. Maringá: EDUEM.

GOMES, Nilma Lino. Indagações sobre currículo: diversidade e currículo. Brasília: Ministério da Educação, Secretaria de Educação Básica, 2007.

HARAWAY, Donna J. Manifesto ciborgue Ciência, tecnologia e feminismo-socialista no final do século XX. In: HARAWAY et al. Antropologia do ciborgue: as vertigens do pós-humano. Belo Horizonte: Autêntica, 2009.

IBGE. Estatísticas de gênero: uma análise dos resultados do Censo Demográfico 2010. Rio de Janeiro, RJ, 2014.

JÚNIOR, Durval Muniz de Albuquerque. Máquina de fazer machos: gênero e práticas culturais, desafio para o encontro das diferenças. In: SIMILI, Ivana Guilherme (org.). Corpo, gênero e sexualidade. Maringá: Eduem, 2011.

LOPES, Alice Casimiro; MACEDO, Elizabeth (Orgs.). Políticas de currículo em múltiplos contextos. São Paulo: Cortez, 2006.

NETO, Marcus Bentes de Carvalho. Análise do comportamento: behaviorismo radical, análise experimental do comportamento e análise aplicada do comportamento. In: Interação em Psicologia, p. 1-7, jan/jun. 2002.

OGASAWARA, Jenifer Satie Vaz. O conceito de aprendizagem de Skinner e Vygotsky: um diálogo possível. Trabalho de Conclusão de Curso (Graduação) Universidade do Estado da Bahia. Departamento de Educação. Colegiado de Pedagogia. Campus I, 2009.

REGIONAL SUL 2. Mensagem à igreja e ao povo do Paraná. Disponível em: <http://cnbbs2.org.br/site/2015/03/mensagem-a-igreja-e-ao-povo-do-parana/>. Acesso em: 01 de ago. de 2015.

SILVA, Tomaz Tadeu da. O currículo como fetiche: a poética e a política do texto curricular. Belo Horizonte: Autêntica, 2010. 
SKINNER, B. F. Tecnologia do ensino. Ed. da Universidade São Paulo, São Paulo, 1972.

SKINNER, B. F. Ciência e comportamento humano. São Paulo, $11^{\mathrm{a}}$ ed. Martins Fontes, 2003.

\section{Como referenciar este artigo}

CASTELEIRA, Rodrigo Pedro; MAIO, Eliane Rose. Gênero, volte para o armário! Discurso religioso, gênero e modelagem de comportamento. Revista Ibero-Americana de Estudos em Educação, Araraquara, v.12, n.1, p. 243-257, 2017. Disponível em: $<$ http://dx.doi.org/10.21723/riaee.v12.n1.8137>. E-ISSN: 1982-5587.

Data de submissão: out/2015

Aprovação final: dez/17 